\title{
Antimicrobial Activities of Selected Medicinal Plant with Potential Role of Chemical Compounds
}

\author{
Aysha Iftikhar ${ }^{1}$, Adnan Shahid ${ }^{2 *}$, Syed Saifullah Shah ${ }^{1},{\text { Sajid } \text { Ali }^{2}, \text { Mohsin Raza }}^{2}$, Ebadet Ali $^{3}$, Shaheena Umbreen ${ }^{4}$ \\ ${ }^{1}$ Department of Botany, University of Agriculture, Faisalabad, Pakisthan \\ ${ }^{2}$ Institute of Microbiology, University of agriculture Faisalabad, Pakisthan \\ ${ }^{3}$ Department of Botany, Hazara University, Mansehra, Dhodial, Mansehra, Khyber Pakhtunkhwa 21120, Pakistan \\ ${ }^{4}$ Department of Botany, University of Okara, 2-KM, Renala Khurd - Okara Road, G.T. Road, Okara، N-5، Okara, Punjab 56300, Pakistan
}

\begin{abstract}
DOI: $10.36348 /$ sipm.2020.v05i11.004
| Received: 10.10 .2020 | Accepted: 24.10.2020 | Published: 16.11 .2020
\end{abstract}

*Corresponding author: Adnan Shahid

\section{Abstract}

Several studies about the medicinal plants provide the evidences about the chemical compounds found in onions. These compounds included the catechole as well as ferulic acids, quercetin and kaempferol. The efficiency of the kaempferol has maximum as compared to the quercetin to inhibit the growth of the B.cereus. The antimicrobial activity of the plants has been precisely studied in the experimental investigations. The ultimate goal of all chemicals obtaining from the plants to target the major groups of the bacteria that causes diseases in human body, fishes and also other animals. There are certain gaps in literature about the different activities of the extracts of the onion. The antimicrobial activity of the onion extract remains unclear because of different microbes such as E.coli and S.aureus showing the resistance against the particular compound. Several relevant data and other research based studies showed comprehensive relationship to the antimicrobial activity of the onions in vitro against the different types of the microbes that causes different diseases such as Escherichia coli, Salmonella shigella, Vibrio cholera and Staphylococcus aureus. Quercetin and its related compounds possess the sulphur as a functional group. So, onions broadly used to treat the medical related disease in such a way that less side effected products obtaining from the plant in comparison to the industry that completely synthesized the products chemically and hence has more side effects.

Keywords: Medicinal Plants, Biochemical effects, Antimicrobial activity, lipid peroxidation.

Copyright (C) 2020 The Author(s): This is an open-access article distributed under the terms of the Creative Commons Attribution 4.0 International License (CC BY-NC 4.0) which permits unrestricted use, distribution, and reproduction in any medium for non-commercial use provided the original author and source are credited.

\section{INTRODUCTION}

There are certain chemical compounds that work against most of the species of bacteria. A study using the chemical called 3-quercetin-8-yl-2,3epoxyflavanone shows the activity against the bacteria such as multi-drug resistant $S$. aureus that actually the most dangerous strain of the bacteria which causes resistance to many of drugs. $H$. pylori which also the strain of the bacteria causes problems in the stomach and causes problems in the system associated with digestion also shows the resistance to many of the drugs [1].

The antimicrobial activity of the plants has been precisely studied in the experimental investigations. There are several plants that possess the specific chemicals in their inner as well as outer parts. These chemicals obtained from the large variety of plants showing activities against the pathogenic form of bacteria [2]. The extracts obtained from the plants effective suitable for prevention as well as inhibition of growth of bacteria. The extract obtained from the specific plant such as onion shows antimicrobial activity. A lot of data have been recently published in favors of the biochemical activities of the onion. The extracts obtained from onion have been demonstrated the antimicrobial activity in vitro studies. The ultimate goal of all chemicals obtaining from the plants to target the major groups of the bacteria that causes diseases in human body, fishes and also other animals $[2,3]$.

Several studies about the medicinal plants provide the evidences about the chemical compounds found in onions. Onion as a major type of plant that was used as a food in past for cooking and other industrial processes. It exhibits the potential compounds that significantly work against different types of infections. These compounds also show activity against microbes due to resistance against microbial diseases. Extract of the onion has been used against the infection to certain 
microorganisms such as fungi and mostly bacteria [4$6]$.

Onion also possess the sulphur which inhibited the growth of microbes that causes certain diseases and has been act as potential protective chemical agent against certain varieties of microbes. These chemical compounds effectively showed antimicrobial activity that inhibited the growth of microbes. These compounds included the catechol as well as ferulic acids, quercetin and kaempferol. The efficiency of the kaempferol has maximum as compared to the quercetin to inhibit the growth of the B.cereus. The important phenolic compounds that present in red type of onion have maximum activity against free radicals $[7,8]$.

There are certain gaps in literature about the different activities of the extracts of the onion. The antimicrobial activity of the onion extract remains unclear because of different microbes such as E.coli and S.aureus showing the resistance against the particular compound. The further study needed to understand the nature of different chemical compounds in onion that responsible for antimicrobial activity for better understanding of molecular mechanism of the different pathogens that causing different diseases in the human [9].

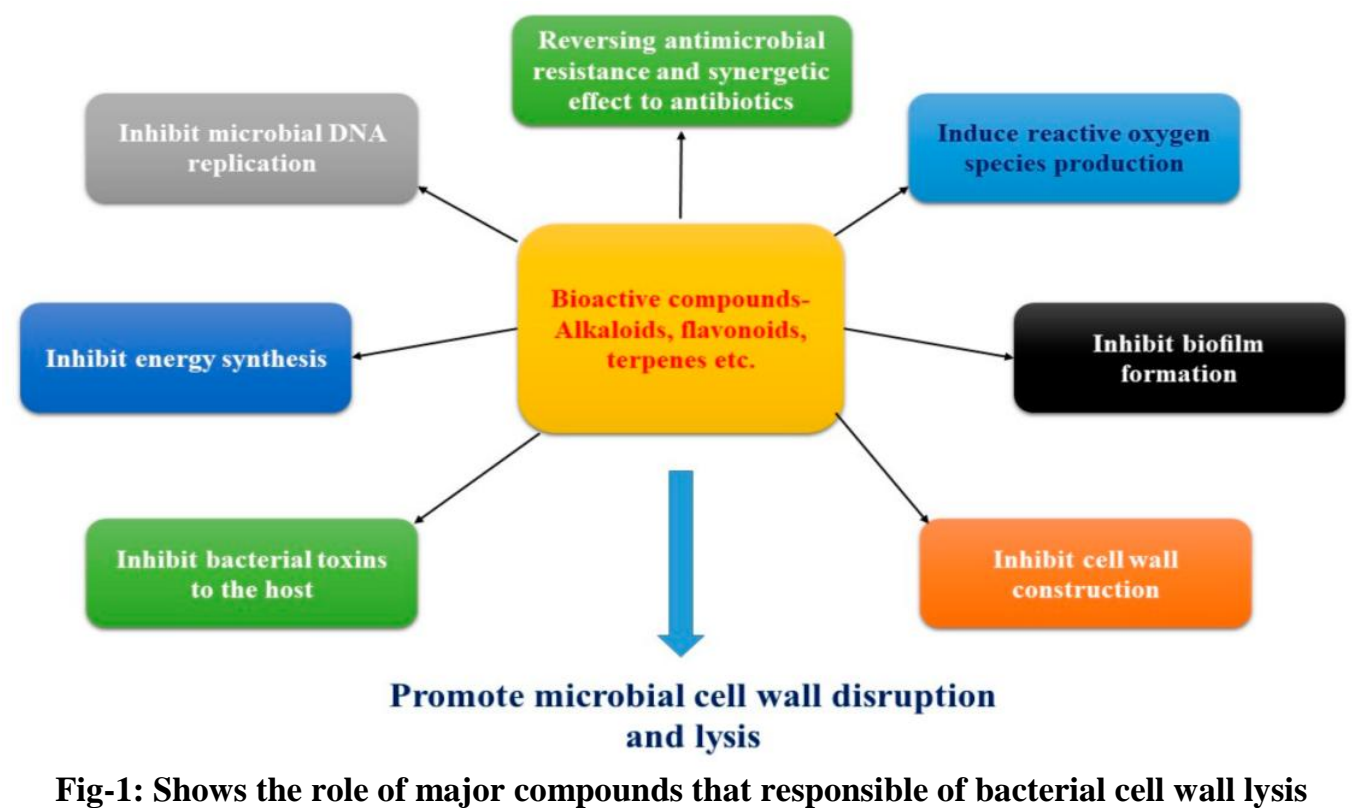

\section{Compounds with Antimicrobial activity}

The onion has much significant value in comparison to the other plants because it contains numerous chemicals compounds such as flavonoids as well as terpenoids that responsible for its antimicrobial activity. The normal concentrations of chemical compounds much more important to treat the diseases caused by bacteria. It was experimentally investigated that more concentration of these compounds increased the more chances of toxicity caused by onions [10].

These compounds that actually involved in making the composition of onions and increases its activity against the various forms of pathogens as well as bacteria. The other compounds that playing significant role in contributing the antimicrobial activity included the alkaloids as well as tannins. These compounds obtained from the plants and have low toxicity level while in comparison to the drugs and other harmful compounds that synthesized in industries. The antimicrobial activity of the onions mainly due to presence of the compounds related to sulphur containing that biochemically functions against the microbes especially dental diseases $[11,12]$.
Due to active and high concentration of the chemicals especially sulphur in the onions showed strong antimicrobial activity and one the example included the dental caries. Several relevant data and other research based studies showed comprehensive relationship to the antimicrobial activity of the onions in vitro against the different types of the microbes that causes different diseases such as Escherichia coli, Salmonella shigella, Vibrio cholera and Staphylococcus aureus. These harmful types of the microbes that affected the major population of the human badly and overall involved in spreading of infections. In vitro based experimental studies showed that red types of the onions also possess the high antimicrobial activity against the some of the bacteria such the Helicobacter pylori that causes infections in the digestive system and their high concentrations also leads directly a cancer in the ulcer. So, onions were used in the past as well as currently for the prevention of the infection ulcer and also reduced the chances of the ulcer. One of the chemical that found in the onions was the quercetin that responsible for antimicrobial and especially targeted the viruses [13, 14]. 


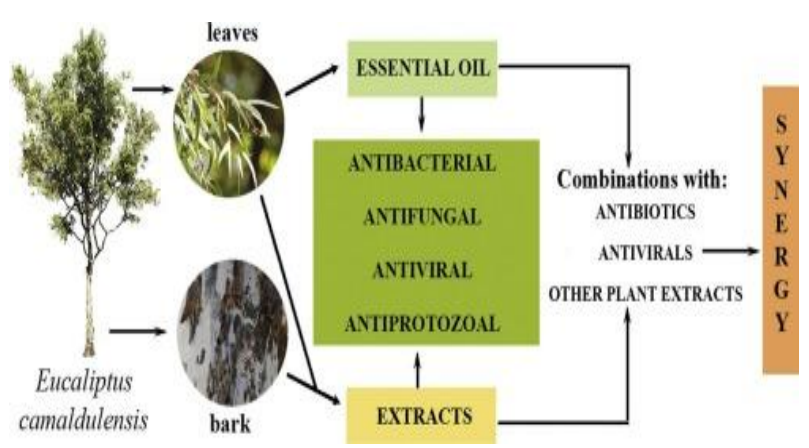

Fig-2: Shows the different parts of plants with bioactivities

\section{Role of Quercetin and other compounds}

Quercetin and its related compounds possess the sulphur as a functional group. It was studied that less or low level of the quercetin found in the onions, then its activity against the specific virus effectively was decreased. Some of the latest studies about the medicinal plants that effectively used as a source of food and helping to treat the diseases caused by viruses. One of the experimental research showed that the working activity against the viruses mainly due to presence of the other compounds related to the flavonoids [15-17].

Onions posses the highest concentration of the flavonoids that acting on the surface of the viruses and also damaged the membrane of the viruses. As a result, virus cannot grow due to the presence of high level of flavonoids. It also contains the special proteins called lectins that significantly involved in attaching the molecules of sugars with biological parameters. Several relevant data and other research based studies showed that comprehensive relationship to the antimicrobial activity of the onions in vitro against the pathogenic forms of different microbes such as Aspergillus niger,
Candida albicans and Saccharomyces cerevisiae. These most harmful types of the microbes that affected the population of the human badly and overall increased the rate of infection in the current age $[18,19]$.

The main targeted groups of the lectins in the plants and onions included the viruses. These proteins when attached the sugar to specific type of the virus and then virus cannot pass through proliferation in the body. So, these proteins showed activity against viruses by the formation of the attachment. It also helped to degrade the core of the virus by attaching the membrane of viruses [20].

In vitro experimental based studies showed that lectins involved for damaging the membrane of the HIV virus. One of the example of the lectins activity against the virus by the involvement in the synthesis of drug that work effectively against the virus due to HIV that mainly transferrred by the sexual activity as well as the blood transfusion. Scientists found that lectins the most suitable proteins that found in the inner portion of the onions. These proteins experimentally proven in the laboratory of research of the USA. There modifications in the structure of the lectins done by scientist and checked its function against viruses. The result significantly favored in controlling the overall growth of viruses. The use of and search for drugs and dietary supplements derived from plants have accelerated in recent years. Ethnopharmacologists, botanists, microbiologists, and natural-products chemists are combing the Earth for phytochemicals and "leads" which could be developed for treatment of infectious diseases. While 25 to $50 \%$ of current pharmaceuticals are derived from plants, none are used as antimicrobials [21-24].

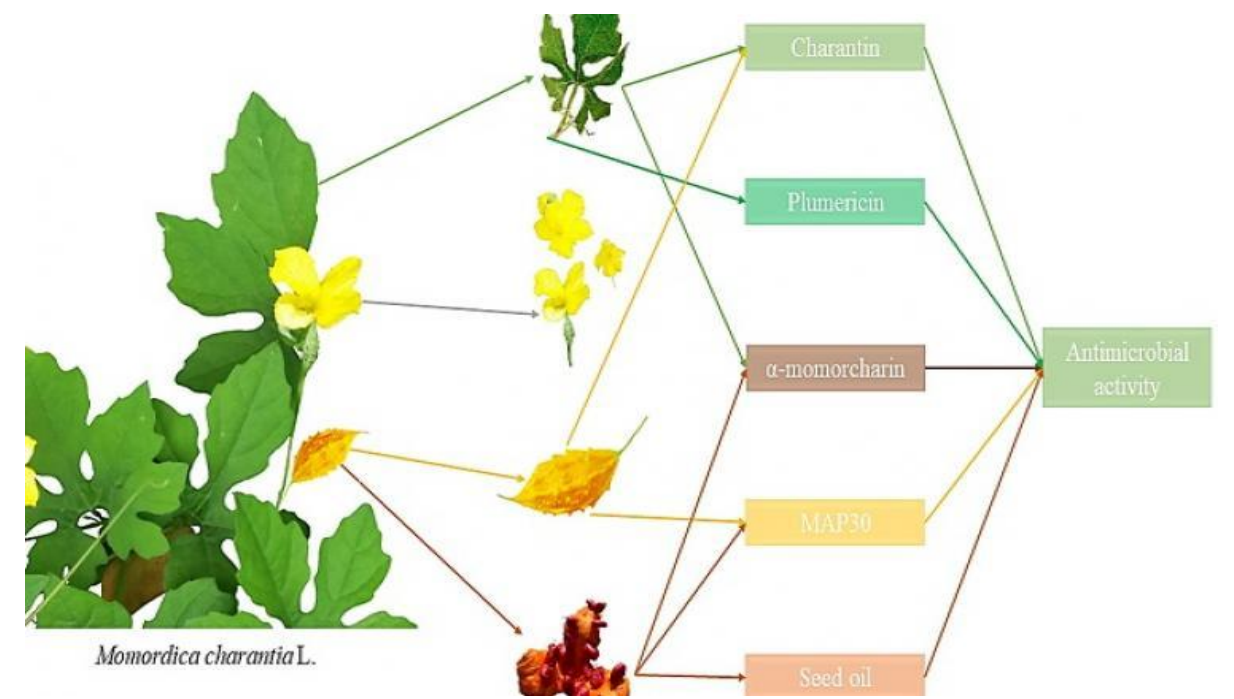

Fig-3: Shows the different parts of plants with compounds has antimicrobial activity

There are lots of bacteria that cause diseases in human as well as children. A large number of populations entire the world significantly affected due to infections caused by bacteria. It has become severe health issue in the fields of medical sciences. The bacteria which cause diseases in the populations of 
human are Escherichia coli, Salmonella shigella, Vibrio cholera and Staphylococcus aureus. These bacteria enter from the specific type of environment such as food, water and also the air and ultimately enter into the body to spread the infections by releasing the chemicals that are endotoxin and as well as exotoxin in the nature and some cases both types of infections also leads to increase in severity of disease of the living organisms. These bacteria have increases chances to grow in the living system. When they found the living source, then they grow rapidly inside the cells also damaging the cells. Many bacteria causing a lot diseases in the populations of human. Over the last seven decades, applications using members of the Bacillus subtilis group have emerged in both food processes and crop protection industries. Their ability to form survival endospores and the plethora of antimicrobial compounds they produce has generated an increased industrial interest as food preservatives, therapeutic agents and biopesticides. The bacteria when enters into the body of living system, started growth rate in the targeted cell. Many symptoms appeared when bacterial attack prominently occurred on the cells of the living system [25-28].

The living system ultimately damaged to the other parts of body because bacteria when causing the infections in living cell, then bacteria also releases a lot of harmful chemicals which significantly damaged the body. Immune system released antibodies in response to bacteria that released chemical for the specific infection. The specific antibodies initially targeted to the cells of bacteria then ultimately killed the cells of the specific bacteria that usually attacked on the body. Immune system of the living system became weak or failed to give response to specific bacteria, then chances of attack and as well as infections increases to the specific living cells. Bacteria also causes a lot of diseases in human as well as children. A variety of pathogenic form of bacteria significantly damaged the populations around the world. It has become the global issue due to incases number of diseases in relation to pathogenicity and resistance of bacteria [29-32].

\section{CONCLUSION}

Onions contains compounds that work against the viruses as well as on bacteria. These compounds included the sulphur and other related families lectins and quercetin. It also inhibited the replication of the major group of the fungi. So, onions broadly used to treat the medical related disease in such a way that less side effected products obtaining from the plant in comparison to the industry that completely synthesized the products chemically and hence has more side effects.

\section{REFERENCES}

1. Arora, D. S., \& Kaur, J. (1999). Antimicrobial activity of spices. International journal of antimicrobial agents, 12(3), 257-262.
2. Balouiri, M., Sadiki, M., \& Ibnsouda, S. K. (2016). Methods for in vitro evaluating antimicrobial activity: A review. Journal of pharmaceutical analysis, 6(2), 71-79.

3. Cushnie, T. T., \& Lamb, A. J. (2005). Antimicrobial activity of flavonoids. International journal of antimicrobial agents, 26(5), 343-356.

4. Cho, K. H., Park, J. E., Osaka, T., \& Park, S. G. (2005). The study of antimicrobial activity and preservative effects of nanosilver ingredient. Electrochimica Acta, 51(5), 956-960.

5. Elsherbiny, D. A., Abdelgawad, A. M., El-Naggar, M. E., El-Sherbiny, R. A., El-Rafie, M. H., \& ElSayed, I. E. T. (2020). Synthesis, antimicrobial activity, and sustainable release of novel $\alpha$ aminophosphonate derivatives loaded carrageenan cryogel. International Journal of Biological Macromolecules, 163, 96-107.

6. Hussain, A., Rafeeq, H., Asghar, A., Ullah, S., Imtiaz, U., Ullah, H., ... \&amp; Ilyas, M. D. Combined inhibitory potential of Ammonium thiosulphate and 2-chloro-6-(trichloromethyl) pyridine on ureases activities.

7. Lemire, J. A., Harrison, J. J., \& Turner, R. J. (2013). Antimicrobial activity of metals: mechanisms, molecular targets and applications. Nature Reviews Microbiology, 11(6), 371-384.

8. Muñoz-Bonilla, A., \& Fernández-García, M. (2012). Polymeric materials with antimicrobial activity. Progress in Polymer Science, 37(2), 281339.

9. Mwafy, E. A., Hasanin, M. S., \& Mostafa, A. M. (2019). Cadmium oxide/TEMPO-oxidized cellulose nanocomposites produced by pulsed laser ablation in liquid environment: synthesis, characterization, and antimicrobial activity. Optics \& Laser Technology, 120, 105744.

10. Hammer, K. A., Carson, C. F., \& Riley, T. V. (1999). Antimicrobial activity of essential oils and other plant extracts. Journal of applied microbiology, 86(6), 985-990.

11. Nathan, C. F., \& Hibbs Jr, J. B. (1991). Role of nitric oxide synthesis in macrophage antimicrobial activity. Current opinion in immunology, 3(1), 6570.

12. Naeem, M., Hayat, M., Qamar, S. A., Mehmood, T., Munir, A., Ahmad, G., ... \& Hussain, A. (2019). Risk factors, genetic mutations and prevention of breast cancer. Int. J. Biosci, 14(4), 492-496.

13. Usman, G., Muhammad, N., Hamza, R., Usman, I., Ayesha, A., Saqib, U., ... \& Fatima, Q. (2019). A Novel Approach towards Nutraceuticals and Biomedical Applications. Scholars International Journal of Biochemistry, 2(10), 245-252.

14. Nostro, A., Germano, M. P., D'angelo, V., Marino, A., \& Cannatelli, M. A. (2000). Extraction methods and bioautography for evaluation of medicinal plant antimicrobial 
activity. Letters in applied microbiology, 30(5), 379-384.

15. Ruparelia, J. P., Chatterjee, A. K., Duttagupta, S. P., \& Mukherji, S. (2008). Strain specificity in antimicrobial activity of silver and copper nanoparticles. Acta biomaterialia, 4(3), 707-716.

16. Rafeeq, H., Arshad, M. A., Amjad, S. F., Ullah, M. H., Muhammad, H., Imran, R. K., ... \& Ajmal, H. Effect of Nickel on Different Physiological Parameters of Raphanus Sativus.

17. Rafeeq, H., Tanvir, K., Khan, M. A. B., Basit, I., U1, Q., Ain, F. F., ... \& Siddique, S. An Effective Approach towards Heavy Metals and their Effects on Different Organs of the Body.

18. Asim, H., Naima, N., Ayesha, L., Misbah, W., Maryam, A., \& Nida, A. (2020). A Comprehensive Review on Diabetic Retinopathy and Mental Disorders. IOSR Journal of Biotechnology and Biochemistry. 6(3):38-51.

19. Salman, M., Saba, Q., Asim, H., Asma, A., Rubab, S., Sara, Z., \& Noman, N. (2020). Antifungal Properties of Copper Nanoparticles against Aspergillus Niger. Scholars International Journal of Biochemistry, 3(4): 87-91.

20. Ullah, S., Hussain, A., Asghar, A., Ali, H., Ullah, K., Ilyas, M. D., ... \& Kiran, I. (2020). Establishment of Mouse Model for Obesity and Type 2 Diabetes and Expression of Secreted Frizzled Related Protein 4 (SFRP- 4) As A Biomarker. Scholars International Journal of Biochemistry, 3(3):59-66.

21. Ansari, N., Hussain, A., Kiran, I., Ajaz, M. H., Azam, T., \& Ghafoor, A. (2020). Applications of Biotechnological Techniques in Healthcare, Current Advancements and Future Directions. Scholars International Journal of Biochemistry, 3(3):67-72.

22. Ali, J., Hussain, A., Maqsood, S., Imtiaz, U., Laeeq, R., Zulfiqar, M., ... \& Hussain, I. Genetic Basis and Risk Factors Associated with Breast Cancer. International Journal of Scientific and Research Publications. 9.

23. Maryam, P., Syed, N. S., Asim, H., Salman, M., Usman, I., Haris A., Saifur, R., Sayyad, H. M., Sidra, R., Arzoo, R., \& Sadia, Z. (2019). Applications of DNA barcoding and future directions. Journal of Biodiversity and Environmental Sciences.
24. Othman, L., Sleiman, A., \& Abdel-Massih, R. M. (2019). Antimicrobial activity of polyphenols and alkaloids in middle eastern plants. Frontiers in microbiology, 10, 911.

25. Makvandi, P., Wang, C. Y., Zare, E. N., Borzacchiello, A., Niu, L. N., \& Tay, F. R. (2020). Metal- based nanomaterials in biomedical applications: Antimicrobial activity and cytotoxicity aspects. Advanced Functional Materials, 1910021.

26. Roy, A., Bulut, O., Some, S., Mandal, A. K., \& Yilmaz, M. D. (2019). Green synthesis of silver nanoparticles: biomolecule-nanoparticle organizations targeting antimicrobial activity. RSC advances, 9(5), 2673-2702.

27. Rajendran, R., \& Basha, N. S. (2010). Antimicrobial activity of crude extracts and fractions of Premna serratifolia Lin. root. Medicinal Plants-International Journal of Phytomedicines and Related Industries, 2(1), 3338.

28. Srinivasan, D., Nathan, S., Suresh, T., \& Perumalsamy, P. L. (2001). Antimicrobial activity of certain Indian medicinal plants used in folkloric medicine. Journal of ethnopharmacology, 74(3), 217-220.

29. Singh, R., Jain, A., Panwar, S., Gupta, D., \& Khare, S. K. (2005). Antimicrobial activity of some natural dyes. Dyes and pigments, 66(2), 99102.

30. Ghani, U., Bukhari, S. S. H., Ullah, S., Rafeeq, H., Saeed, M. M., Amjad, A., \&amp; Taufiq, T. (2019). A review on Nutraceuticals as a Therapeutic Agents. International Journal of Biosciences, 15(5), 326-340.

31. Vogelman, B., \& Craig, W. A. (1986). Kinetics of antimicrobial activity. The Journal of pediatrics, 108(5), 835-840. Yu, H. H., Kim, K. J., Cha, J. D., Kim, H. K., Lee, Y. E., Choi, N. Y., \& You, Y. O. (2005). Antimicrobial activity of berberine alone and in combination with ampicillin or oxacillin against methicillin-resistant Staphylococcus aureus. Journal of medicinal food, 8(4), 454-461.

32. Zaika, L. L. (1988). Spices and herbs: their antimicrobial activity and its determination. Journal of Food Safety, 9(2), 97-118. 